\title{
As profissões em saúde e o Serviço Social: desafios para a formação profissional
}

\author{
Líria Maria Bettiol Lanza \\ Universidade Estadual de Londrina (UEL) \\ Fabrício da Silva Campanucci \\ Universidade Estadual de Londrina (UEL)
}

Letícia Orlandi Baldow

Universidade Estadual de Londrina (UEL)

\begin{abstract}
As profissões em saúde e o Serviço Social: desafios para a formação profissional
Resumo: O objetivo deste estudo bibliográfico é compreender como o Serviço Social tem enfrentado o processo de revisão da formação profissional ofertada para o trabalho em saúde. Inicia pela compreensão do que vem a ser uma profissão em saúde, localizando o Serviço Social e sua vinculação com a área destacando o aspecto formativo. Dessa forma, verifica que é legítima a configuração do Serviço Social como profissão em saúde, tanto do ponto de vista conceitual como do ponto de vista prático, evidenciado pela vinculação histórica da profissão e por sua utilidade social nos serviços de saúde. Ainda, aponta para os desafios da atuação profissional no contexto conflituoso da política de saúde brasileira e suas implicações na formação profissional.

Palavras-chave: Profissões em saúde. Serviço Social. Formação profissional.
\end{abstract}

\section{Healthcare Professions and Social Work: Challenges for Professional Education}

Abstract: The objective of this bibliographic study is to understand how Social Work has faced the process of revising the professional education offered for work in healthcare. It begins with the understanding of what is a healthcare profession, locating Social Work and its ties with the field and highlighting educational aspects. In this way, it verifies that it is legitimate to configure Social Work as a healthcare profession, both from a conceptual and practical perspective, revealed by the historic ties of the profession and its social utility in healthcare services. It also points to the challenges to professional activity in the conflictive context of Brazilian healthcare policy and its implications for professional education.

Keywords: Healthcare professions. Social Work. Professional education. 


\section{Introdução}

A contemporaneidade possui traços de uma sociedade profissionalizada e alicerçada no trabalho especializado, fruto do processo de industrialização em que os antigos ofícios foram se configurando com contornos mais profissionalizantes (SCHWEITZER, 2008). Somam-se a isso, a crescente divisão técnica do trabalho, a lógica de mercado e as demandas profissionais que se atualizam e se reveem no desenvolvimento de determinadas economias. Nesse sentido, as profissões encontram-se intimamente ligadas à lógica capitalista e ao seu movimento histórico, havendo oscilações que demandam análises aprofundadas sobre o que de fato revelam.

É clássica a assertiva de que as profissões fornecem um trabalhador especializado - detentor de um "saber complexo" - e que deve ter uma utilidade social. Isto significa que o resultado de sua ação - ou seu trabalho profissional - deve ser capaz de atender a uma necessidade humana. Assim, na mesma medida em que as necessidades são cada vez mais ampliadas, os trabalhadores e seu trabalho também o são.

Cabe aqui destacar que para se compreender as características das profissões em saúde ${ }^{1}$ é necessária uma análise sobre vários ângulos, que busque identificar qual a relevância do "existir" de uma profissão na sociedade.

A fim de refletir sobre o Serviço Social enquanto uma profissão em saúde, bem como sobre as demandas para a formação profissional, esta revisão bibliográfica está estruturada em três eixos. Inicialmente, nos estudos das particularidades das profissões em saúde, seguido da caracterização do Serviço Social no trabalho nessa área e, por fim, elucida alguns desafios presentes na relação trabalho e formação profissional em saúde.

\section{As características das profissões em saúde}

Na sociedade capitalista, a demanda por trabalhadores abrange todos os níveis de formação, sejam eles básicos, técnicos ou superiores. No entanto, existe uma cultura nacional na qual o diploma de estudos em nível superior é hipervalorizado socialmente, em termos financeiros e na manutenção do status quo, e sua falta inferioriza as ocupações com menor grau de instrução.

Esta questão possui motivações históricas. Em séculos anteriores, cursar uma graduação era privilégio apenas de uma elite e o surgimento tardio da universidade no Brasil favoreceu essa perspectiva que perdura até hoje (CUNHA, 1986).

Por mais que a sociedade tenha mudado e o ensino superior tenha sido ampliado, sobretudo no setor privado, e que novas profissões tenham surgido, ain- da persiste a herança do status social para as profissões tidas como "mais tradicionais". Um bom exemplo é a Medicina, considerada a profissão em saúde por excelência e uma das mais cotadas quando o quesito é reconhecimento, seja pela questão econômica ou pelo destaque e relevância social.

Segundo Franzoi (2008, p. 329), foi a partir da década de 1960 que a

[...] literatura sobre as profissões começou a esclarecer o caráter histórico e social do processo de hierarquização intra e entre grupos profissionais. [...] As novas abordagens passam a entender a formação dos grupos profissionais como uma disputa pelo monopólio de mercado, inserida na divisão social do trabalho, mostrando também que o caráter mais ou menos científico do conhecimento monopolizado por cada grupo profissional não é dado, mas socialmente construído.

Sob o olhar de Machado (1996, p. 44), o termo profissão indica uma atividade praticada pelos indivíduos em tempo integral, com uma "estrutura organizativa marcadamente corporativa" que possui um acentuado "componente vocacional", ancorada em um código de ética e que "desenvolve saber específico, apresenta forte orientação para serviço e mantém alto grau de autonomia no trabalho".

Para a autora, as profissões que atuam na área da saúde estão embebidas das características acima assinaladas. Além disso, pela própria natureza do setor, a saúde exige que as atividades laborais sejam executadas por profissionais "com domínio de técnicas e habilidades específicas" (MACHADO, 1996, p. 44).

No entanto, é preciso esclarecer que o fato dos profissionais de saúde serem obrigatoriamente especializados não isenta o setor da subalternização de determinadas profissões e do cerceamento da autonomia desses profissionais em relação ao próprio trabalho. Ao contrário, as relações de poder entre as diferentes profissões estão presentes nos mais diversos ramos de atividade e legitimam-se hierarquicamente de acordo com nível de especialização: técnico ou superior.

Segundo o Ministério da Educação (BRASIL, 2007), o ensino de nível superior privilegia conteúdos como Ciência, Letras e Arte, agregando um número maior de disciplinas e privilegiando o enfoque teórico, já que há mais tempo para que se desenvolva um estudo com vistas ao incentivo à pesquisa e à produção do conhecimento.

No caso dos cursos técnicos, a formação é mais ágil e voltada exclusivamente para o exercício do trabalho. Deste modo, abrange apenas as disciplinas necessárias à função, oferecendo um retorno mais rápido na procura de uma vaga no mercado de trabalho. 
Alguns autores, como Pereira e Ramos (2006), têm destacado a crescente valorização do ensino técnico no Brasil em detrimento do ensino superior e denunciado a política governamental neoliberal. Orientada pelo Banco Mundial, tal estratégia fomenta a formação aligeirada e focada na mão de obra para atender as exigências de aumento da produtividade pelo mercado.

Tal entendimento encontrou eco nos Ministérios do Trabalho e da Educação, atraindo investimento público para viabilizar a abertura de cursos, convênios e parcerias de incentivo à capacitação. Entretanto, orientado pela ideologia da empregabilidade, esse modo de investir em qualificação profissional transfere para o trabalhador a responsabilidade de conquistar seu espaço no competitivo mundo do trabalho, deixando claro o cariz neoliberal dos incentivos estatais para formação profissional no Brasil.

No que diz respeito às profissões em saúde, o Sistema Único de Saúde (SUS) assume a responsabilidade de acompanhar o desenvolvimento de políticas de formação dos profissionais de saúde, como previsto no artigo 15, inciso IX, da Lei Orgânica da Saúde (BRASIL, 1990).

Uma abordagem mais ampla considera parte desse coletivo qualquer indivíduo que trabalhe na área. Outras preferem ainda - mesmo considerando a ampliação dos diferentes profissionais - trabalhar com a denominação "pessoal de saúde" (BETTIOL, 2010).

Dentro de uma linha sociológica, o perfil profissional caminha na divisão sociotécnica do trabalho. Embora se agrupem em uma definição mais genérica de "trabalhadores em saúde" ou "pessoal de saúde", as profissões possuem diferentes formações e recortes verticais em que têm graus diferenciados de autonomia e poder. Dessa forma, os profissionais alcançam diferentes tipos de trabalho assalariado, que variam de acordo com suas especialidades.

Ancorados em uma base sindicalista, há os que consideram o conjunto dos profissionais da saúde "trabalhadores da saúde", designação que abarca profissionais diversificados que não têm, necessariamente, uma ligação específica com a saúde, como o pessoal administrativo e o da limpeza.

Diferenciações à parte, é consenso que o setor de saúde é um dos maiores existentes (mesmo se precarizado), além de altamente diversificado. Para alguns autores, como Machado (2005), a crescente incorporação de novas tecnologias gera a necessidade de novas ocupações, sobretudo aquelas de fundo técnico.

Frequentemente, dificuldades nas ações de assistência e na produção do cuidado são atribuídas ao trabalhador da saúde e à sua base formativa. No entanto, a assistência oferecida, condições e contextos de trabalho ou questões técnicas podem estar, na maior parte, ligadas a questões institucionais, princi- palmente em tempos de ataque às políticas sociais. Os baixos recursos financeiros investidos, associados à frágil gestão do trabalho e da educação, têm configurado a saúde como uma área em débito com a sociedade brasileira.

Todavia, como necessidade humana e afirmação da vida, a saúde ainda demonstra vitalidade e continua a mobilizar profissionais, militantes, pesquisadores e usuários na superação de problemas e na busca do atendimento integral, público e de qualidade.

Assim, as profissões da área da saúde ganham proeminência na sociedade pela complexidade de todo o conhecimento adquirido durante a sua formação e à habilidade que se deve possuir para executar suas múltiplas ações e enfoques, sobretudo ao trazer para a cena o usuário e seu modo de viver, conviver e produzir.

Nesse sentido, concorda-se com Carvalho e Ceccim (2009, p. 157) quando enfatizam que há profissões em saúde com núcleos de competências ligados à assistência e outras às práticas de promoção à saúde.

Para ser um profissional de saúde há necessidade do conhecimento científico e tecnológico, mas também de conhecimento de natureza humanística e social relativo ao processo de cuidar, de desenvolver projetos terapêuticos singulares, de formular e avaliar políticas e de coordenar e conduzir sistemas e serviços de saúde.

Para os autores, "o conjunto de profissões de saúde, aprende, trabalha e reconstrói no cotidiano a Grande Área [Ciências da Saúde], ao mesmo tempo em que aprofunda, aperfeiçoa e especializa cada área, subárea ou especialidade" (CARVALHO; CECCIM, 2009, p. 156).

Essa reflexão encontra escopo no conceito ampliado de saúde e no princípio da integralidade, deflagrados pela Constituição Federal de 1988, que sinalizaram o alargamento do que se considera, inclusive nos marcos jurídicos legais, profissões em saúde. No contexto do Serviço Social, merece destaque a Resolução n. 218, de 06 de março de 1997, do Conselho Nacional de Saúde, que determinou o conjunto das profissões em saúde e nele incluso o Serviço Social.

\section{Serviço Social como uma profissão em saúde}

Na reflexão sobre o trabalho dos assistentes sociais é relevante destacar que esses profissionais atuam nas manifestações da questão social e no modo como elas interagem com a política social, "mediação incontornável na constituição do trabalho profissional" (IAMAMOTO, 2007, p. 185). 
O enfrentamento da questão social pelo Estado evidencia o papel das políticas sociais e indica como as mesmas traduzem a correlação de forças entre o Estado e as demandas da classe trabalhadora. É nesta disputa que se move o trabalho profissional do assistente social.

No que se refere à saúde, Bravo (1996, p. 13) salienta que este é "um dos setores mais significativos na atuação do Serviço Social, tendo concentrado historicamente um grande quantitativo de profissionais, situação que permanece até os dias correntes".

Para apresentar de que forma os assistentes sociais estão inseridos neste âmbito de atuação e marcar seu posicionamento acerca da concepção de Serviço Social, faz-se necessário indicar que essa profissão emerge no evolver da conjuntura de 1930 e se consolida no Brasil a partir de 1945 em consonância com a expansão do capitalismo no país (BRAVO, 2009).

As discussões travadas entre os assistentes sociais que teorizam "a natureza e o processo da gênese do Serviço Social” revelam duas concepções que, para Montaño (2009, p. 17), constituem verdadeiras "teses, claramente opostas, sobre a gênese do Serviço Social".

Uma delas, com "perspectiva endogenista", sustenta a origem da profissão "na evolução, organização e profissionalização" das formas de ajuda - sejam elas de princípio religioso ou filantrópico - que agora se vinculam à intervenção na "questão social" (MONTAÑO, 2009, p. 20).

Já a segunda tese ${ }^{2}$, na mesma linha desta pesquisa, assume uma perspectiva "histórico-crítica" que trilha um caminho de análise oposto. Tal abordagem

[...] entende o surgimento da profissão do assistente social como um produto da síntese dos projetos político-econômicos que operam no desenvolvimento histórico, onde se reproduz material e ideologicamente a fração de classe hegemônica, quando, no contexto do capitalismo na sua idade monopolista, o Estado toma para si as respostas à 'questão social' [...] entende-se o assistente social como um profissional que desempenha um papel claramente político, tendo uma função que não se explica por si mesma, mas pela posição que o profissional ocupa na divisão sociotécnica do trabalho (MONTAÑO, 2009, p. 30).

De acordo com Bravo (2009), no Brasil, os assistentes sociais começaram a ser requisitados no setor saúde a partir de 1945, no contexto do processo de expansão do capitalismo e das mudanças internacionais geradas pelo fim da Segunda Guerra Mundial. Soma-se a essas características conjunturais o conceito de saúde voltado a "aspectos biopsicossociais" adotado pelos organismos internacionais, que gerou a necessidade de convocar outros profissionais para atuar nesta área, incluindo os assistentes sociais.

Uma das consequências da adoção deste conceito de saúde foi a ênfase no trabalho multidisciplinar, utilizado, dentre outros motivos, para preencher a falta de profissionais e racionalizar o setor saúde. Com equipes compostas por diversos "auxiliares", buscava-se disseminar informações com conteúdo preventivista, ampliar a abordagem em saúde "e criar programas prioritários com segmentos da população, dada a inviabilidade de universalizar a atenção médica e social" (BRAVO, 2009, p. 199).

As contradições geradas pelo formato contributivo que caracterizavam os serviços de saúde no Brasil também influenciaram o exercício profissional do assistente social nesta área. Como o acesso a saúde não era universal - nem nos termos da lei -, seu caráter seletivo e excludente colocou estes profissionais entre a instituição hospitalar e a população, desenvolvendo atividades que tinham a finalidade de viabilizar a utilização dos serviços e benefícios, mas que, devido ao caráter seletivo dos mesmos, cristalizavam práticas que mais excluíam do que incluíam.

Seguindo a lógica desenvolvimentista do Brasil, o Serviço Social recebeu as influências da modernização conservadora na década de 1960, "sedimentando sua ação na prática curativa, principalmente na assistência médica previdenciária" (BRAVO, 2009, p. 202), adentrando a década de 1970 sem grandes alterações.

Enquanto as conquistas constitucionais da década de 1980 eram comemoradas pelos brasileiros, o Serviço Social iniciava uma fase de amadurecimento da "tendência atualmente hegemônica na academia e nas entidades representativas da categoria - a intenção de ruptura - e, com isso, a interlocução real com a tradição marxista" (BRAVO, 2009, p. 204).

O problema é que boa parte dos assistentes sociais que compartilhava desta vertente, inseriram-se nas universidades. Deste modo, a perspectiva crítica adotada por esses profissionais teve pouca intervenção nos serviços, isto é, na prática profissional.

Bravo (2009, p. 205) destaca que ainda são insuficientes os avanços conquistados pelo exercício profissional de assistentes sociais na saúde devido ao fato de a profissão ter chegado à década de 1990 "com uma incipiente alteração do trabalho institucional", por permanecer "desarticulada do Movimento de Reforma Sanitária" e pela pequena contribuição no que se refere às questões colocadas à categoria na prática em saúde.

"Considerando que os anos noventa foi o período de implantação e êxito ideológico do projeto neoliberal no país, identifica-se que, nesse contexto, os dois projetos políticos em disputa na área da saúde" - o privatista e o sanitarista -, "passam a apresentar diferentes requisições para o Serviço Social" (BRAVO, 1998, apud CFESS, 2010, p. 26). 
Com base em Escorel (1989), Bravo (1996) salienta que a saúde pode ser considerada um componente fundamental da democracia e da cidadania e um campo privilegiado da luta de classes. Nessa perspectiva, a prática do Serviço Social encontra-se intimamente ligada à estrutura de classes e sofre determinações estruturais e conjunturais da sociedade.

Por um lado, destacam-se entre as demandas postas para a categoria profissional pelo projeto privatista: a seleção socioeconômica dos usuários, a atuação psicossocial, a fiscalização dos usuários dos planos de saúde e o "assistencialismo por meio da ideologia do favor e predomínio de práticas individuais" (CFESS, 2010, p. 26).

Por outro, o projeto de reforma sanitária solicita a contribuição do Serviço Social em questões ligadas ao acesso aos serviços de saúde, à busca de estratégias para aproximar as ações em saúde da realidade, ao trabalho interdisciplinar, à ênfase nas abordagens grupais com vistas a atender o maior número de pessoas possível, ao acesso democrático às informações e ao estímulo à participação popular.

Nota-se, portanto, que há uma relação entre o projeto ético-político ${ }^{3}$ e o de reforma sanitária, principalmente, nos seus grandes eixos: "principais aportes e referências teóricas, formação profissional e princípios" (CFESS, 2010, p. 26). Além disso, observase que a grande bandeira continua sendo a implementação do projeto de Reforma Sanitária. E nesta luta, cabe aos assistentes sociais buscar estratégias que possibilitem a efetivação do direito à saúde, prestando serviços diretos à população, sejam eles no âmbito da gestão, planejamento, mobilização ou participação social.

Isto significa que a atual conjuntura conclama profissionais articulados aos movimentos sociais, de trabalhadores e usuários, que não se cansam de lutar por um SUS de qualidade; pelo acesso universal em todos os níveis de complexidade, com ações e serviços complementares, capazes de integrar as equipes de saúde e estimular a intersetorialidade, viabilizando a participação dos usuários e dos trabalhadores nas decisões a serem tomadas.

É pertinente destacar que, para Bravo (1996), os assistentes sociais atuam nas instituições de saúde para administrar a tensão que existe entre as demandas postas pela população e os limitados recursos para a prestação de serviços. Deste modo, o exercício profissional mantém as características observadas, como a triagem e a seleção socioeconômica.

Ao descrever algumas características da prática profissional dos assistentes sociais, Iamamoto (1992, p. 100-101) esclarece que os profissionais desempenham funções tanto de "suporte à racionalização do funcionamento" das entidades das quais são vinculados - organismos estatais, paraestatais ou privados - como
[...] funções técnicas propriamente ditas. Do ponto de vista da demanda, o Assistente Social é chamado a constituir-se no agente intelectual de 'linha de frente' nas relações entre instituição e população, entre os serviços prestados e a solicitação desses mesmos serviços pelos interessados.

Regulamentado pela Lei n. 8.662 de 1993 e por um Código de Ética Profissional (1993), o Serviço Social apresenta-se na cena contemporânea como uma profissão analítica e interventiva, com uma série de atribuições e competências fundadas na garantia de direitos sociais e na construção de uma sociedade verdadeiramente democrática, sem preconceitos e iniquidades sociais.

Na perspectiva de atenção integral em saúde, as demandas sociais emergem de várias formas no cotidiano do trabalho do Assistente Social. Comumente exigem a intervenção profissional na viabilização do acesso a consultas, exames, internações e tratamentos. Sendo assim,

As ações a serem desenvolvidas pelos assistentes sociais devem transpor o caráter emergencial e burocrático, bem como ter uma direção socioeducativa por meio da reflexão com relação às condições sócio-históricas a que são submetidos os usuários e mobilização para a participação nas lutas em defesa da garantia do direito à Saúde (CFESS, 2010, p. 43).

Afinal, esta intervenção abrange as mudanças que ocorrem no cotidiano do indivíduo e também de seus familiares, provocadas, dentre outros fatores, pela hospitalização, pelo desconhecimento do cidadão em relação ao diagnóstico/tratamento, pelo agravamento da situação financeira, pela ansiedade e medo da doença, pelo preconceito e discriminação, pela dificuldade de acesso aos serviços e aos profissionais, pela necessidade de insumos, violência e até mesmo pela agilização de alta hospitalar.

Diante do exposto, pode-se afirmar que as demandas que se apresentam ao Serviço Social envolvem uma série de condicionantes e exigem uma intervenção profissional que não se limite à prática curativa, mas que inclua aspectos preventivos, informativos e de promoção da saúde. Para tanto,

O profissional precisa ter clareza de suas atribuições e competências para estabelecer prioridades de ações e estratégias, a partir de demandas apresentadas pelos usuários, de dados epidemiológicos e da disponibilidade da equipe de saúde para ações conjuntas (CFESS, 2010, p. 43).

Cabe aqui complementar que a inserção dos assistentes sociais no contexto do SUS também ocorre pela efetivação do princípio da integralidade da aten- 
ção à saúde, que pressupõe uma ação interdisciplinar e intersetorial (NOGUEIRA; MIOTO, 2009). A integração da prevenção, promoção e recuperação da saúde, contempladas no acesso aos três níveis de complexidade do SUS, é um dos principais sentidos dessa proposta.

Segundo Cecílio (2001, p. 116), a integralidade da assistência à saúde apresenta diferentes dimensões. Uma delas é a "integralidade focalizada" que é desenvolvida nos serviços de saúde por equipes multiprofissionais e pode ser definida "como o esforço da equipe de saúde de traduzir, atender, da melhor forma possível, tais necessidades [de saúde], sempre complexas, mas, principalmente, tendo que ser captadas em sua expressão individual".

Outra dimensão apresentada pelo autor é denominada "integralidade ampliada", devendo ser concebida como "relação articulada, complementar e dialética, entre a máxima integralidade no cuidado de cada profissional, de cada equipe e da rede de serviços de saúde e outros" (CECÍLIO, 2001, p. 120).

Trata-se, portanto, de viabilizar à população o acesso não só a todos os níveis de complexidades do SUS, mas a todas as políticas e serviços sociais que todo cidadão brasileiro tem direito. Prática que exige profissionais com um cabedal de conhecimento tanto sobre as políticas e legislações quanto sobre a rede de serviços sociais para promoverem tal integração. Exigências que também se aplicam ao exercício profissional do assistente social.

Nogueira e Mioto (2009, p. 225) ressaltam que, como o princípio da integralidade sustenta-se nos pilares da interdisciplinaridade e da intersetorialidade, ele não só possibilita como justifica uma "inserção diferenciada do assistente social na área da saúde, superando o estatuto de profissão paramédica, típico do modelo biomédico".

Dessa forma, é necessário que o assistente social que atua nessa área aprofunde seus conhecimentos para ser capaz de entender suas origens e desdobramentos e dominar certos conhecimentos epidemiológicos e administrativos que conformam o agir em saúde. No entanto, em recente avaliação da Abepss (UCHÔA, 2009), é possível verificar certa defasagem na formação profissional dos assistentes sociais para a atuação em saúde e que deve ser enfrentada pelas instituições de ensino superior (IES).

\section{Os desafios da formação profissional para o trabalho em saúde}

As mudanças na saúde exigiram que as profissões se adaptassem ao contexto do SUS, desencadeando um processo de revisão das instituições formadoras dos trabalhadores em saúde (BETTIOL, 2010). No caso do Serviço Social, esta revisão se inclui num quadro mais amplo de discussões profissionais que vinham ocorrendo desde meados da década de 1960 com o Movimento de Reconceituação na América Latina. Neste ínterim, houve uma aproximação do Serviço Social às Ciências Sociais que deu base para as discussões sobre os processos técnico-profissionais, teóricometodológicos e ético-políticos, e abriu espaço para uma reavaliação da própria face social e ideológica da profissão. No Brasil, a luta profissional juntou-se à luta da sociedade por democracia e incitou a discussão do novo projeto profissional, que culminou com o projeto ético-político.

Em 1988, a Constituição Federal contemplou boa parte das reivindicações sociais, principalmente na área da saúde. A partir de então, esta passa a ser reconhecida como um direito universal e resultado das condições de alimentação, transporte, lazer, acesso e posse de terra, educação, meio ambiente, trabalho, habitação, renda e acesso a serviços de saúde.

Apesar da década de 1990 ter sido fundamental para a perspectiva dos direitos sociais, no caso específico da saúde houve um ataque dos agentes financeiros internacionais que pregavam as contrarreformas no contexto da crise do capital monopolista, refutavam o caráter universal e público e visavam a mercantilização e a privatização da saúde. Para a superação da crise, os organismos internacionais como o Fundo Monetário Internacional (FMI), o Banco Mundial e a Organização Mundial do Comércio (OMC), impõem às Nações em desen- 
volvimento a adoção de medidas de liberalização, desregulamentação e privatização, sobretudo das políticas sociais.

A desresponsabilização do Estado das suas funções, como protagonista dos serviços prestados à população, não surge nesse momento, mas se agrava. Apesar da obrigação descrita na Constituição Federal, o poder público repassa à sociedade civil parte da responsabilidade de lidar com a questão social, o que faz com que o Estado tenda a focalizar as políticas em detrimento do caráter universal das mesmas. Essa interferência, no caso da saúde, principalmente do Banco Mundial, dá-se pela rentabilidade do setor, que envolve os grupos privados de saúde, a indústria farmacêutica e de equipamentos (CORREIA, 2007).

Deste modo, ocorre uma atualização dos projetos de saúde em disputa no Brasil, o que a vincula como direito social universal, atraindo o privatista que encontra na mercantilização sua materialidade. É no contexto da contrarreforma que os assistentes sociais têm vislumbrado novas requisições que oscilam dos processos de gestão, sobretudo aqueles vinculados à produtividade, eficiência e eficácia dos serviços voltados às ações emergenciais que reproduzem "a lógica individualista, curativa e predominantemente assistencial" (SOARES, 2012, p. 105).

Nesse sentido, é fundamental para qualquer profissional em saúde entender os determinantes sociais que a constituem, não somente no que diz respeito à organização política, mas no aspecto da gestão e na sua relação com os usuários. Ou seja, nesses aspectos diversos é a cultura da população que mantém e legitima o modelo de saúde atual.

Todavia, como afirma Mourão et al. (2006), devido ao incentivo à fragmentação e especialização infinita, o processo de formação de quadros profissionais dificilmente atua baseado no trabalho interdisciplinar visando a saúde coletiva. Nesse caso, o esforço não é apenas de uma ou outra profissão, mas de toda a equipe envolvida, no sentido de definir um projeto de saúde capaz de fazer frente ao projeto neoliberal, mercantilista, que domina as políticas sociais no mundo capitalista.

Sem essa contextualização e base teóricometodológica, tem-se uma visão a-histórica e focalista. Volta-se ao positivismo e reduz-se a atuação profissional ao empirismo e ao pragmatismo, como explicita Iamamoto (2006), que também traz as perspectivas do trabalho do assistente social frente à cena contemporânea. Torna-se necessário que o profissional apreenda as expressões e os processos de produção e reprodução ampliada e fomente a criação de formas de resistência e defesa da democratização das relações sociais. Isso só é possível a partir de um perfil crítico que deriva do projeto de formação profissional.
No caso da área em estudo, a construção de novos modelos de fazer saúde com base na integralidade, intersetorialidade e atuação em equipe, só será efetiva quando houver uma mudança na prática e na formação do profissional em saúde. Isso vem em consonância com Bravo e Matos (2009, p. 213) que afirmam que "as novas diretrizes das diversas profissões têm ressaltado a importância de formar trabalhadores de saúde para o Sistema Único de Saúde com visão generalista e não fragmentada".

$\mathrm{O}$ assistente social, em especial, devido a sua formação generalista, necessita ter esse conhecimento histórico da política de saúde, da epidemiologia, dos mecanismos de gestão entre tantas outras ferramentas. Assim, poderá identificar os determinantes do processo saúde-doença e propor intervenções específicas e intersetoriais na busca pela saúde integral, articulando organicamente os saberes teóricos apropriados pela categoria, e expressos nas próprias diretrizes curriculares para os cursos de Serviço Social, com a realidade cotidiana dos serviços e das políticas sociais nos quais os profissionais atuam. Para isso, o projeto profissional já assinala a ênfase numa formação acadêmica qualificada e permanente, para que haja uma nova relação com os usuários, tornando-os sujeitos das ações profissionais.

Contudo, não se deve esquecer que o trabalho em saúde para o profissional do Serviço Social conjuga saberes ligados às Ciências Sociais se afastando do campo das Ciências da Saúde. Portanto, o profissional precisa aprofundar-se na ligação entre o biológico e as condições sociais. É um esforço que a profissão exige, sobretudo, em relação aos conteúdos oferecidos durante o curso de graduação.

Nesse sentido, vale a pena retomar a reflexão de Mourão et al. (2006, p. 374),

É na perspectiva da atenção integral que o profissional de Serviço Social estrutura seu processo de trabalho no interior das equipes de saúde. Com uma abordagem individual e coletiva constrói sua prática na perspectiva do direito e da ampliação da cidadania contribuindo, com um aporte teórico metodológico sobre o processo saúde-doença, para o avanço das reflexões e possibilidades de atuação interdisciplinar no cuidado à saúde.

Não se pode ignorar o processo mais amplo em que se insere o ensino superior no país. A educação, principalmente no que diz respeito ao nível superior, tem sido sistematicamente sucateada no âmbito público por corte de verbas, tendência a privatizações, ingerências de entidades e órgãos "pseudopúblicos” que visam o lucro e ferem o princípio da autonomia universitária.

No âmbito privado, a formação para o mercado, aligeirada por vezes nos moldes do ensino a distância, avança a passos largos. Este contexto impacta a 
formação profissional, inclusive dos profissionais em saúde, quando nos currículos os conteúdos, estágios supervisionados e outros espaços formativos, privilegiam a visão curativa, lucrativa, especializada e descontextualizada da saúde em detrimento da saúde integral, universal, pública e compromissada com os interesses da coletividade.

\section{Considerações finais}

O exame sobre o exercício profissional dos assistentes sociais na saúde indica a existência de práticas democráticas e limites da atuação profissional. Observa-se ainda que a atuação dos assistentes sociais reclama uma leitura crítica da realidade aliada à defesa intransigente dos direitos dos cidadãos. Particularmente, a saúde exige um profissional vinculado à luta pelo acesso equânime às ações e aos serviços, ao trabalho interdisciplinar e ao estímulo à participação social, buscando efetivar a universalidade do acesso à saúde - em sua concepção ampliada - determinada constitucionalmente e reafirmada na legislação complementar.

Tais requisições incidem no projeto de formação profissional da categoria. $\mathrm{O}$ estudo sobre o processo ensino/aprendizagem com foco no ensino de graduação evidenciou a urgência em introduzir e aprofundar as discussões acerca da saúde nos projetos pedagógicos de cada IES. Ademais, deve-se privilegiar o enfoque no exercício profissional. Nesse sentido, pode-se tomar a saúde como um espaço importante para essa empreitada, já que congrega elementos como a atuação essencialmente interdisciplinar e relacional, que contribuem no desenvolvimento de habilidades fundamentais para a profissão, como a comunicação, escuta ativa, construção de projetos terapêuticos singulares e um domínio fundamental do campo disciplinar para a atuação em equipe.

Ressalta-se, ainda, a necessidade de formação constante por meio da educação continuada que engloba um esforço do ser profissional para o compromisso com a qualidade dos serviços prestados. Envolve desde a busca por cursos de especializações lato sensu até o incentivo às residências profissionais, multidisciplinares, além da importância dos estudos produzidos no âmbito da pós-graduação stricto sensu que nutre a profissão dos debates e experiências que abarcam a saúde e as políticas sociais.

\section{Referências}

BETTIOL, L. M. Atualizando o debate: formação profissional, trabalho em saúde e Serviço Social. 2010. Tese (Doutorado em Serviço Social) - Pontifícia Universidade Católica de São Paulo, São Paulo, 2010.
BRASIL. Lei n. 8.080, de 19 de setembro de 1990. Dispõe sobre as condições para a promoção, proteção e recuperação da saúde, a organização e o funcionamento dos serviços correspondentes e dá outras providências. Brasília, 1990.

Ministério da Educação. Educação profissional técnica de nível médio integrada ao Ensino Médio: documento base. Brasília, 2007. Disponível em: <http://portal.mec.gov.br/setec/ arquivos/pdf/documento base.pdf>. Acesso em: 15 jan. 2012.

BRAVO, M. I. S. Serviço Social e reforma sanitária: lutas sociais e práticas profissionais. Rio de Janeiro: Cortez, 1996.

Política de saúde no Brasil. In: MOTA, A. E. et al. (Org.). Serviço Social e saúde: formação e trabalho profissional. São Paulo: Cortez, 2009, p. 88-110.

BRAVO, M. I. S.; MATOS, M. C. Projeto ético-político do Serviço Social e sua relação com a reforma sanitária: elementos para o debate. In: MOTA, A. E. et al. (Org.). Serviço Social e saúde: formação e trabalho profissional. São Paulo: Cortez, 2009, p. 197-217.

CARVALHO, Y. M.; CECCIM, R. B. Formação e educação em saúde: aprendizados com a saúde coletiva. In: CAMPOS, G. W. S. et al. Tratado de saúde coletiva. São Paulo: Hucitec; Rio de Janeiro: Fiocruz, 2009.

CECÍLIO, L. C. de O. As necessidades de saúde como conceito estruturante. In: PINHEIRO, R.; MATTOS, R. A. (Org.). Os sentidos da integralidade na atenção e no cuidado à saúde. Rio de Janeiro: UERJ, IMS: Abrasco, 2001, p. 113-126.

CORREIA, M. V. C. A saúde no contexto da crise contemporânea do capital: o Banco Mundial e as tendências da contrarreforma na política de saúde brasileira. Temporalis, Brasília, v. 13, p. 11-38, 2007.

CUNHA, L. A. A universidade temporã. Rio de Janeiro: Livraria Francisco Alves Editora, 1986.

ESCOREL, S. Saúde: uma questão nacional. In: TEIXEIRA, S. F. (Org.). Reforma Sanitária em busca de uma teoria. São Paulo: Cortez/Abrasco, 1989, p. 181-192.

FRANZOI, N. L. Profissão (Verbete). In: PEREIRA, I. B.; LIMA, J. C. F. (Org.). Dicionário da educação profissional em saúde. Rio de Janeiro: EPSJV, 2008, p. 328-333.

IAMAMOTO, M. V. O Serviço Social na divisão do trabalho. In:__ Renovação e conservadorismo no Serviço Social: ensaios críticos. São Paulo: Cortez, 1992, p. 87-112.

. As dimensões ético-política e teórico-metodológica no Serviço Social contemporâneo. In: MOTA, A. E. et al. (Org.). Serviço Social e saúde: formação e trabalho profissional. São Paulo: Cortez, 2006, p. 161-196. 
Serviço Social em tempo de capital fetiche: capital financeiro, trabalho e questão social. São Paulo: Cortez, 2007.

MACHADO, M. H. As profissões e o SUS: arenas conflitivas. Divulgação em Saúde para Debate, n. 14, p. 44-47, 1996.

Trabalhadores da saúde e sua trajetória na Reforma Sanitária. In: LIMA, N. T. (Org.). Saúde e democracia: história e perspectivas do SUS. Rio de Janeiro: Fiocruz, 2005, p. 257-281.

MIOTO, R. C. T.; NOGUEIRA, V. M. R. Sistematização, planejamento e avaliação das ações dos Assistentes Sociais no campo da Saúde. In: MOTA, A. E. et al. (Org.). Serviço Social e saúde: formação e trabalho profissional. São Paulo: Cortez, 2009, p. 273-303.

MONTAÑO, C. A natureza do Serviço Social na sua gênese. In: . A natureza do Serviço Social. São Paulo: Cortez, 2009.

MOURÃO, A. M. A. et al. A formação dos trabalhadores sociais no contexto neoliberal: o projeto das residências em Saúde da Faculdade de Serviço Social da Universidade Federal de Juiz de Fora. In: MOTA, A. E. et al. (Org.). Serviço Social e saúde: formação e trabalho profissional. São Paulo: Cortez, 2006, p. 352-380.

PAULO NETTO, J. A construção do projeto ético-político do Serviço Social. In: MOTA, A. E. et al. (Org.). Serviço Social e saúde: formação e trabalho profissional. São Paulo: Cortez, 2006, p. $141-160$.

PEREIRA, I. B.; RAMOS, M. N. Educação profissional em saúde. Rio de Janeiro: Fiocruz, 2006.

SCHWEITZER, S. As mulheres e o acesso às profissões superiores. Uma comparação europeia, séculos XIX e XX. In: COSTA, A. do; SORJ, B.; BRUSCHINI, C.; HIRATA, H. (Org.). Mercado de trabalho e gênero: comparações internacionais. Rio de Janeiro: FGV, 2008, p. 371-385.

SOARES, R. C. A racionalidade da contrarreforma na política de saúde e o Serviço Social. In: BRAVO, M. I. S.; MENEZES, J. S. B. (Org.). Saúde, Serviço Social, movimentos sociais e conselhos. São Paulo: Cortez, 2012, p. 85-108.

UCHÔA, R. Resultados da pesquisa. Serviço Social: interfaces com a saúde. In: ABEPSS. Política de Saúde e Serviço Social: impasses e desafios. Temporalis, São Luís, ano VII, n. 13, p. 151-183, jan./jun. 2007.

\section{Notas}

1 Esta pesquisa conta com a colaboração das estudantes de graduação em Serviço Social da Universidade Estadual de Londrina (UEL) Jéssica Furuhata Inácio e Vanessa de Souza Novaes, que foi fundamental para a realização deste trabalho.
2 Esta concepção da emersão e legitimação da profissão "Serviço Social" é defendida principalmente por "Marilda Vilela Iamamoto, Raul de Carvalho, Manuel Manrique Castro, Vicente de Paula Faleiros, Maria Lúcia Martinelli, José Paulo Netto, entre outros" (MONTAÑO, 2009, p. 30).

3 Este projetoé resultado de um longo e coletivo processo construído nas últimas três décadas e tem seus valores e pilares pautados no Código de Ética Profissional, na Lei n. 8.662/93, que regulamenta a profissão e nas Diretrizes Curriculares aprovada pela Associação Brasileira deEnsinoe Pesquisa em Serviço Social (Abepss). "Afirma a defesa intransigente dos direitos humanos e o repúdio do arbítrio e dos preconceitos, contemplando positivamente o pluralismo, tanto na sociedade como no exercício profissional" (PAULO NETTO, 2006, p. 155).

\section{Líria Maria Bettiol Lanza}

liriabettiol@uel.br

Doutora em Serviço Social pela Pontifícia Universidade Católica de São Paulo (PUC-SP)

Professora adjunta do Departamento de Serviço Social da Universidade Estadual de Londrina (UEL)

\section{Fabrício da Silva Campanucci}

fabricio.fsc@hotmail.com

Assistente social e mestrando do Programa de PósGraduação em Serviço Social e Política Social na UEL

\section{Letícia Orlandi Baldow}

leticia_orlandi@yahoo.com.br

Graduanda em Serviço Social na UEL

\author{
UEL - Departamento de Serviço Social \\ Campus Universitário \\ Caixa Postal 6001 \\ Londrina - Paraná \\ CEP: 86051-980
}

